\title{
UNIVERSIDADE POPULAR E AGROECOLOGIA: DIÁLOGO DE SABERES E PRÁTICAS
}

\author{
AUTOR: FERNANDO SILVA CAMPOS \\ CO-AUTOR/ORIENTADOR: DIRCEU BENINCA
}

Resumo: A agroecologia é uma importante proposta teórica e prática capaz de promover uma visão ecossistêmica da realidade, a valorização do modus vivendi da agricultura familiar, o cuidado com o meio ambiente e com a saúde integral, bem como a integração de grupos e comunidades que constituem o território Extremo Sul da Bahia. A Universidade Federal do Sul da Bahia (UFSB), enquanto instituição de cunho científico, popular e crítico, pode contribuir significativamente com o fortalecimento da agroecologia e, de maneira mais ampla, com o desenvolvimento humano, social e econômico das comunidades regionais. Este projeto teve por objetivos: conhecer a dinâmica de produção de alimentos agroecológicos no referido território; verificar a aceitabilidade, pelos consumidores, desses produtos comercializados em feiras na cidade de Teixeira de Freitas; analisar a relação entre agroecologia e saúde no contexto da pandemia do Covid-19. Tratou-se de um estudo qualitativo. No início do projeto, foram realizados alguns diálogos com feirantes e consumidores da Feira da Agricultura Familiar na UFSB e noutras feiras da cidade. Com o surgimento da pandemia e a suspensão de todas as atividades presenciais na UFSB, as entrevistas e diálogos que estavam planejados foram substituídos por pesquisas bibliográficas, participação em conferências virtuais e lives. A revisão bibliográfica, aprofundada a partir de então, procurou compreender os seguintes conceitos: universidade popular; agroecologia; crise sistêmica e pandemia. Foi possível diagnosticar percepções muito positivas a respeito da Feira da Agricultura Familiar na UFSB, baseada exclusivamente na agroecologia. Todos os consumidores consultados mostraram-se satisfeitos com a dinâmica de comercialização direta dos produtos e com a sua qualidade. Verificou-se a necessidade de maior divulgação da Feira da UFSB e das demais feiras da cidade. Percebeu-se o reduzido apoio do governo municipal às feiras da agricultura familiar de base agroecológica. Constatou-se que a pandemia do novo coronavírus expôs de forma clara as contradições, crises e iniquidades do sistema capitalista. O estudo demonstrou a relevância da agroecologia na produção de alimentos saudáveis, na preservação e restauração do meio ambiente, no fortalecimento da economia solidária e no enfrentamento de crises sistêmicas, a exemplo da pandemia do novo coronavírus.

Palavras-chave: Agroecologia, Universidade Popular, Desenvolvimento Sustentável. 